\title{
CONCEITOS FUNDAMENTAIS DOS MÉTODOS PROJETIVOS
}

Elza Rocha Pinto

Elza Rocha Pinto
Professora da
Universidade
Federal do Rio de
Janeiro (UFRJ),
com especialização
em Psicologia
Clínica (PUC-
RJ), mestrado em
Psicologia (UFRJ),
doutoranda em
Saúde Pública no
Programa Saúde da
Criança e da Mulher
(IFF/Fiocruz).

Elza Rocha Pinto Federal do Rio de Janeiro (UFRJ), com especialização em Psicologia Clínica (PUCRJ), mestrado em Psicologia (UFRJ) doutoranda em ca no Criança e da Mulher
RESUMO: O objetivo deste artigo é colaborar para fortalecer a confiança no uso dos métodos projetivos nos processos de avaliação psicológica. As associações produzidas frente aos estímulos ambíguos são consideradas expressões da personalidade. Tendo a psicanálise como cenário principal, faremos aqui a exposição de alguns conceitos teóricos que colaboram para a interpretação dos materiais projetivos. São examinados três conceitos: a projeção e suas diferentes variações, a elaboração de fantasias e a personificação. Em seguida, são apresentados alguns métodos projetivos, discutindo-se a eficácia projetiva por meio dos desenhos e pinturas.

Palavras-chave: Projeção, personificação, técnicas projetivas, testes psicológicos.

ABSTRACT: Fundamental concepts for projective techniques. The objective of this article is to collaborate to strengthen the trust in the use of the projective methods in processes of psychological diagnosis. The associations produced to the ambiguous materials are considered as expressions of the personality. With the psychoanalysis as the main scenery, this paper exposes some theoretical concepts that make possible the interpretation of the projective materials. In the first part of the paper, four concepts are examined: projection and their different variations, elaboration of fantasies, personification and compromise formation. Soon afterwards, some projective techniques are presented, and the effectiveness of them is illustrated through drawings and paintings.

Keywords: Projection, personification, compromise formation, projective techniques. 


\title{
INTRODUÇÃO
}

\begin{abstract}
"A obra de arte - e sobretudo a obra literária — não se impõe apenas como um objeto de gozo ou de conhecimento; ela se oferece ao espírito como objeto de interrogação, de indagação, de perplexidade." (Gaëtan Picon)
\end{abstract}

Os métodos projetivos foram assim designados por Frank $(1939,1965)$, quando este autor reuniu sob o mesmo termo uma diversidade de testes então utilizados. Seu artigo examinava uma ampla variedade de materiais e de técnicas, utilizadas como meios de acesso às vivências internas, aos conflitos e desejos do sujeito. Frank (1939) achava que as técnicas projetivas ofereciam acesso ao mundo dos sentidos, significados, padrões e sentimentos, revelando aquilo que o sujeito não pode ou não quer dizer, frequentemente por não se conhecer bem. De acordo com este autor, tais métodos podiam apreender aspectos latentes ou encobertos da personalidade, por serem inconscientes.

Existem posições contrárias ao uso do termo projetivo aplicado a alguns destes métodos. Tais restrições normalmente têm por objetivo libertar estes métodos do contexto teórico da psicanálise. No entanto, acreditamos que a manutenção desta terminologia continua sendo útil, pois facilita a identificação destas técnicas - é longa a trajetória que esta designação percorreu. Trata-se de uma especificação de categoria, já que, em função de sua ampla variedade, os testes psicológicos foram submetidos a classificações para facilitar as reflexões e estudos sobre eles. Os critérios de ordenação são diferentes para cada autor. Aqui, seguimos a trilha lançada por Frank (1939), para quem a marca distintiva destas técnicas (com diferentes materiais e tarefas), estaria em sua natureza relativamente não estruturada, ambígua e amorfa, assim como na liberdade da resposta e do tempo diante de estímulos vagos e plásticos. Assim, o material externo precisaria mesmo ser bastante impreciso ou indefinido para criar maiores possibilidades de revelação. Se o material for definido, ao falar sobre ele a pessoa estaria bem próxima de uma descrição objetiva da realidade externa. Sua percepção seria puramente cognoscitiva, como diria Bellak (1967). Ao contrário, diante das indefinições do material, o sujeito está mais próximo de expressar seu mundo interior, quando empresta contornos mais precisos à ambiguidade pela interpretação e atribuição de sentidos.

Os métodos projetivos são utilizados desde o início do século XX. Porém, muitas vezes foram olhados com suspeita por psicólogos que procuram maior segurança nos procedimentos dos testes objetivos. O preconceito contra os testes projetivos foi responsável pelo declínio de seu uso, durante a década de 1960, época em que os testes objetivos ganharam muito prestígio. Se tomarmos uma referência clássica em matéria de testes psicológicos, vamos ver como esta descon- 
fiança atravessa o próprio projeto do livro de Anastasi (1965), que dedica apenas um de seus capítulos aos métodos projetivos. Esta autora desconfia bastante de suas qualidades preditivas, devido ao fraco perfil psicométrico destas técnicas. Ela desqualifica os métodos projetivos inclusive pela falta de objetividade dos resultados: “... mesmo quando se tenham desenvolvido sistemas objetivos de avaliação, os passos finais, na avaliação e integração dos dados brutos, dependem da habilidade e da experiência clínica do examinador" (ANASTASI, 1965, p.614).

Esta posição permanece também em outros textos mais recentes da mesma autora (ANASTASI \& URBINA, 2000). E é até possível ver a influência destas críticas positivistas na proibição ditada pelo Conselho Federal de Psicologia, quando suas normas vetaram o uso de alguns testes (como o CAT, ou as técnicas gráficas). No entanto, é preciso lembrar, como o fazem Abt \& Bellak (1967), que as questões relacionadas à validade e confiabilidade dos procedimentos projetivos precisa ser considerada a partir de uma perspectiva diferente daquela que está subjacente aos estudos dos testes psicométricos.

Anzieu (1988) indica a confluência de duas grandes correntes teóricas na invenção dos métodos projetivos — o Gestaltismo, por um lado, e a Psicanálise, por outro. Já que são escassos os trabalhos que se inserem nesta linha epistemológica, acreditamos ser importante relembrar alguns dos principais conceitos que colaboraram para fundamentar a utilização dos métodos projetivos na prática clínica. Limitaremo-nos aqui a uma breve abordagem de alguns conceitos psicanalíticos que oferecem fundamento para estes métodos: projeção, elaboração das fantasias, personificação e formação de compromisso. Pretendemos assim contribuir para fortalecer a confiança na interpretação dos materiais produzidos por associação livre diante dos materiais utilizados por estas técnicas.

\section{PROJEÇÃO}

O fundamento teórico da hipótese projetiva, explicitada por Frank (1939), deve ser creditado ao conceito de projeção, que teve um longo percurso na obra de Freud. Este autor vai trabalhar o conceito em momentos distintos, com perspectivas bastante diferentes, incorporando conteúdos conscientes e inconscientes. Esta perspectiva é de grande importância, pois retira do conceito sua carga negativa. Não é de se estranhar que ele tenha designado este fenômeno como mecanismo de defesa. É importante lembrar que Freud está trabalhando numa época que sofreu enorme influência da psicologia herbartiana. Na introdução da Edição eletrônica de Freud, James Strachey, discutindo a originalidade do termo recalcamento, reconhece que Herbart, em 1824, já exercia uma grande influência sobre pessoas que conviveram com Freud, em particular seu professor de psiquiatria, Meynert. 
Herbart desenvolveu o último grande sistema de psicologia metafísica, traduzindo as influências filosóficas do idealismo alemão e do empirismo inglês e francês. Em sua metafísica materialista, a noção de defesa era central. Ele compreendia a alma como uma unidade de matéria, indivisível da realidade, e que obedecia às mesmas leis newtonianas que regiam o mundo físico. Da física, o sistema herbartiano incorporou pelo menos dois princípios: "toda ação provoca uma reação", e "a natureza resiste à destruição”. Estes mesmos princípios são encontrados na obra de Freud, pois foi à luz desta psicologia que desenvolveu sua psicanálise. Então, é fácil entender a aposta de Anzieu (1988), que procura fundamentos para a ampliação que Freud imprimiu ao significado do termo projeção, oferecendo à interpretação dos métodos projetivos uma nova geografia, para além do território do inconsciente e da patologia. Isto é encontrado em Herbart (1816/2008), com o conceito de apercepção. E também em Freud, que, para manter a originalidade de sua teoria, precisou evitar cuidadosamente este conceito.

Segundo Herbart (idem), a alma responderia aos estímulos externos por meio de respostas defensivas, às quais ele denominou percepções. As respostas perceptivas aos estímulos externos seriam as defesas autoprotetoras da alma. O sistema herbartiano vai lidar com matéria e energia, já que sua psicologia se enraíza na física. A personalidade é produto de um campo de forças, que podem ser relacionadas entre si, combinadas ou divididas, dirigidas para sentidos idênticos ou opostos, ou mesmo excluídas mutuamente. "Estas forças são percepções, e a dinâmica de Herbart se baseia na luta das percepções para conseguir um lugar na consciência humana. As forças reprimidas ficam submergidas no inconsciente; esforçam-se por ganhar a superfície e algumas vezes o conseguem" (WOLMAN, 1970, p.7-8).

Para explicar a aprendizagem, este autor entrecruzou o conceito de forças físicas com as leis do associacionismo, lançando as bases para o desenvolvimento de várias teorias. Ele acreditava que a massa aperceptiva - espécie de subfator da alma - incorporava percepções novas, por meio da assimilação e da combinação com representações antigas, processo que ele designou de apercepção. Esta massa aperceptiva constituía a "totalidade de percepções conscientes que controla a atividade da alma” (WOLMAN, 1970, p.8). Isto foi escrito antes que Freud constituísse sua teoria psicanalítica, ou que Piaget desenvolvesse a dinâmica dos processos de assimilação e acomodação. A teoria psicanalítica, assim como a construtivista piagetiana, refletem as ideias de Herbart. Em ambas as teorias, o conceito de apercepção ganha uma nova roupagem e designações diferentes. Basta pensar na dinâmica das identificações projetivas para verificar a semelhança, já que nestas, também, a percepção externa e a interna se entrecruzam formando novos significados. A apercepção herbartiana se corporifica pelo jogo 
interativo da introjeção e da projeção. Para Freud, as representações derivadas das percepções internas e externas se entrelaçam formando um corpo de fantasias que constituirá o imaginário. A elaboração destas fantasias obedece à mesma dinâmica interativa incorporada no processo de apercepção.

É possível encontrar, em diversos textos, referências ao processo de deslocamento das representações, que constitui a base do conceito de projeção. Porém, Freud (1911/1948) só vai desenvolver melhor este termo quando examina a biografia do presidente Schreber. Neste momento, a projeção ainda é um conceito limitado, pois trata apenas do deslocamento de sentimentos hostis sobre outra pessoa:

\footnotetext{
“Na produção de sintomas da paranoia ressalta, em primeiro termo, aquele processo que designamos com o nome de projeção. Nele uma percepção interna é reprimida e como sua substituição, seu próprio conteúdo, depois de sofrer uma deformação, vai surgir na consciência como percepção vinda do exterior." (FREUD, 1911/1948, p.686)
}

Bellak (1967) ao subdividir os tipos de projeção, designa esta forma como projeção invertida, já que ela inclui uma operação de transformação no contrário, pelo mecanismo de formação reativa. Antes, Freud já havia feito referência a um sentido mais complexo. Em Psicopatologia da vida quotidiana (1901-1904/1948), no tópico sobre Crença no acaso e superstição, o conceito foi utilizado de uma forma suficientemente ampliada para permitir englobar uma gama maior de fenômenos. Freud trabalha a ideia do determinismo psíquico, e para exemplificar, analisa a crença na superstição. Compara os mecanismos psíquicos do paranoico e do supersticioso. O paranoico, de forma inconsciente, projeta na vida psíquica dos outros aquilo que existe na sua. Quanto ao supersticioso, Freud lembra que essa pessoa, por desconhecer a causa interior, acaba projetando a causalidade psíquica no exterior, distorcendo aperceptivamente a realidade, para usar o termo de Herbart, e interpretando como intencionais determinados fatos que são apenas casuais. Ou seja, o indivíduo vai atribuir uma significação aos fatos externos, sentindo, de algum modo, que estes têm correspondência com seus próprios sentimentos e representações, ocultos por serem inconscientes:

\footnotetext{
“O supersticioso, por ignorar a motivação dos próprios atos casuais e porque o fato desta motivação luta por ocupar um lugar no campo de seu reconhecimento, se vê forçado a transportá-la ao mundo exterior por meio de um deslocamento. (...) Creio, com efeito, que grande parte daquela concepção mitológica do mundo que ainda perdura no fundo das religiões mais modernas não é outra coisa que psicologia projetada no mundo exterior." (FREUD, 1901/1948, p.756)
} 
A projeção, revisitada dentro da vida cotidiana e normal, ganha outra qualidade. Além do significado da expulsão paranoica, passa a representar também o simples desconhecimento, por parte do sujeito, de desejos e emoções que não são aceitas por ele como sendo seus (ou então dos quais é parcialmente inconsciente), e cuja existência atribui à realidade externa.

Esta desterritorialização da geografia da psicopatologia permite que, agora, o conceito se constitua como base de fenômenos tais como o animismo, o pensamento mágico e a onipotência das ideias, todos esses resultantes da projeção dos processos psíquicos primários sobre o mundo exterior. As histórias míticas adquirem o estatuto de formação de compromisso; e podem expressar e elaborar conflitos. Da mesma forma, qualquer associação desenvolvida em resposta a um material de técnicas projetivas.

O desdobramento do termo ganha um contorno definitivo em Totem $e$ tabu. Mitos e tabus contêm fantasias que seriam projeções do psiquismo. O "deslocamento para fora”, o qual é a essência da projeção, mescla-se à atribuição de qualidades ao objeto externo. Algumas vezes, as fantasias são carregadas de afetos negativos e inconscientes, como nas projeções que criam o mito dos demônios e fantasmas. Outras vezes, as projeções carregam fantasias positivas - benéficas e bondosas - , gerando mitos de deuses, anjos e entidades protetoras. E, neste texto, finalmente a projeção sofre o último processo de libertação. Enquanto mecanismo de defesa, para solucionar conflitos, a projeção é inconsciente; porém, Freud (1913/1948) entende que algumas vezes as fantasias projetadas para o exterior podem ser conscientes.

“Porém a projeção não é unicamente um meio de defesa. Podemos observá-la também em casos onde não existe conflito. A projeção para o exterior de percepções interiores é um mecanismo primitivo, ao qual nossas percepções sensoriais se acham também submetidas, e que desempenham um papel essencial em nossa representação do mundo exterior.” (FREUD, 1913/1948, p.454)

Por estes deslizamentos, a projeção vai sendo aplicada a vários fenômenos que fazem parte de nossa vida quotidiana, quando antes esta defesa só se referia à expulsão de desejos intoleráveis e inconscientes em si, tendo sempre um viés patológico. Com a extensão do conceito, passa-se a utilizar a projeção como explicação para o deslocamento de sentimentos, ideias e emoções consideradas positivas e valorizadas, e, até mesmo, conscientes. Este caráter consciente das projeções vai ser bem esclarecido por Bellak (1967), que prefere outra designação para este fenômeno - externalização.

Na década de 1980, Anzieu (1988), retoma algumas considerações da psicologia projetiva de Abt \& Bellak (1967), e atribui três formas diferentes para 
a projeção. No tipo especular, a pessoa age como se estivesse na frente de um espelho, refletindo em seus trabalhos características que reconhece como suas. Quando a projeção ocorre em uma forma complementar, existiria uma atribuição externa de causalidade, e estas causas servem como justificativa de características próprias. Finalmente, na projeção catártica, predominaria o primeiro sentido freudiano, da expulsão de características intoleráveis, quando o sujeito não reconhece determinados sentimentos e ideias como sendo seus, e os atribui a uma origem externa. Quando analisamos as fantasias que surgem em qualquer produção de histórias, composição de desenhos ou outros trabalhos, estes três tipos de projeção podem aparecer de maneira isolada ou mesclada.

\section{ELABORAÇÃO DE FANTASIAS}

Em 1908, Freud escreve um belo artigo no qual analisa os devaneios do artista. Este texto também contribui para a fundamentação teórica dos métodos projetivos. Em O poeta e a fantasia (ano), que na Standard Edition recebe o título de Escritores criativos e devaneio, Freud avança uma explicação sobre o processo da criação, afirmando que existiria uma grande proximidade entre a brincadeira da criança e a obra do artista. "Toda criança que brinca se conduz como um poeta, criando para si mesma um mundo próprio” (1908/1948a, p.965). A diferença estaria no fato do artista brincar apenas em sua imaginação, enquanto a criança precisa de um referente onde apoiar esta imaginação; a criança precisa do brinquedo real.

Para Freud, "a poesia, como o sonho diurno, é a continuação e o substitutivo das brincadeiras infantis" (idem, p.969). Ao crescer, a criança interromperia o seu brincar, aparentemente renunciando ao prazer que extraía até então de seus jogos infantis. Porém, na verdade, não existiria renúncia alguma — apenas uma substituição, na qual o indivíduo vai prescindir "de qualquer apoio nos objetos reais, e em lugar de brincar, ela agora fantasia. Constrói castelos no ar; cria aquilo que chamamos devaneios ou sonhos diurnos" (idem, p.966).

Na literatura, a criação artística vai simbolizar, por meio das palavras, aquilo que o autor pretende dizer. O elemento simbólico — a palavra — substitui assim o referente real. O artista vive intensamente seu mundo interior, apoiando-se não mais nos elementos externos (os brinquedos de quando era criança), mas nos elementos simbólicos, já integrados em sua personalidade adulta.

$\mathrm{Na}$ abordagem freudiana do processo de criação há várias questões a considerar. Não é demais salientar que, para a psicanálise, a criação expressa fantasias e desejos que acabam sendo sublimados. Muitas vezes, o artista sente-se impulsionado ao ato criador, como se tivesse uma necessidade inadiável de ultrapassar seus tormentos, elaborar conflitos e sentimentos contraditórios - 
sublimar, enfim, suas pulsões. Assim, no ato da criação, o processo da sublimação desempenha um papel bastante importante.

Outra questão a ser levada em conta, é a dimensão temporal que se expressa por meio da fantasia criativa. Há três dimensões de tempo a serem atravessadas, sendo a criação o resultado do enlace entre passado, presente e futuro. Para Freud (1908), algo da vivência presente do artista vai se enlaçar a algum acontecimento de seu passado que, então, se expressa pela fantasia concretizada na obra de arte. Por sua vez, esta obra se lança para o futuro, uma vez que cria um mundo inexistente, um mundo virtual — nem presente, nem passado —, um mundo ainda por vir. Para efeito de clareza, é melhor acompanhar Freud desfiar estes tempos: "Assim, pois, o pretérito, o presente e o futuro, aparecem como que entrelaçados pelo fio do desejo, que passa através deles" (1908/1948a, p.967).

A fantasia criadora surge da mesma forma como o sonho, por meio de enlaces múltiplos. No entendimento freudiano (1900/1948), o sonho sempre traduz uma realização de desejos. Fantasias e sonhos diurnos também procuram realizar anseios e expectativas do sujeito. Na verdade, mesmo uma análise superficial revela as vinculações entre a obra e a vida subjetiva do artista. Freud, em seu artigo de 1908, propõe exatamente esta tarefa: “Tentaremos aplicar às obras do poeta nossa tese anterior referente à relação da fantasia com o pretérito, o presente e o futuro e com o desejo que flui através dos mesmos, estudando com sua ajuda as relações dadas entre a vida do poeta e suas criações” (1908/1948a, p.968).

Esta passagem serviu como fundamento para uma série de leituras críticas sobre textos literários e outras obras de arte. Como consequência, tais comunicações colaboraram não apenas para ampliar a compreensão destes textos, como também permitiram um maior entendimento sobre seus autores. E, por sua vez, estes trabalhos serviram para fortalecer as interpretações dos testes temáticos, usados na clínica psicológica.

\section{PERSONIFICAÇÃO}

Existe ainda outro elemento importante a ser registrado, quando os escritores de novelas e contos produzem suas histórias. Estes relatos apresentam uma característica singular, já que todos têm um protagonista, em torno do qual se centra o interesse do autor e dos leitores. É por meio da fala deste herói que se expressa o ego do autor. Segundo a psicanálise, o ego é o real personagem de todos os sonhos e de todas as novelas e romances, mesmo em se tratando das tramas de enredos mais complexos. Freud vai afirmar que a novela psicológica deve sua singularidade “à inclinação do poeta moderno de dissociar seu ego por meio da auto-observação em egos parciais e, em consequência, personificar as 
correntes contraditórias de sua vida mental através de vários heróis" (FREUD, 1908/1948, p.968).

Esta posição de Freud dá margem para algumas reflexões relacionadas com a análise das histórias produzidas diante das técnicas temáticas — como o TAT (Thematic Aperception Test), o CAT (Children Aperception Test, de Bellak, 1967), ou o Maps (Make a Picture Story). Não se trata apenas de apreender motivações inconscientes, ou de caráter defensivo. Sendo o Ego o personagem principal destes relatos, é preciso supor que as histórias estejam expressando também sentimentos, ideias, motivações e fantasias conscientes, pois apreendem competências e habilidades que são funções do Ego (tais como memória, tendências artísticas e outras características da personalidade). Fora as funções defensivas, o Ego desenvolve uma ampla série de atividades, que Freud (1925/1948) examina em Inibição, sintoma e angústia.

Além de fornecer fundamento para uma abordagem mais ampla das respostas aos testes projetivos, dar crédito ao Ego como sendo o protagonista das histórias abriu campo para uma contribuição de Melanie Klein (1964a). Em um artigo datado de 1929 ("A personificação no brinquedo das crianças"), a autora sistematiza e amplia este conceito. Com o brincar, a criança personifica não apenas seu Ego, mas também conteúdos do Id e do Superego, distribuídos pelos diversos personagens pertencentes ao enredo de uma brincadeira. Este recorte é importante para os métodos projetivos, já que alguns se constituem como técnicas lúdicas. Entretanto, entendemos que a personificação não ocorre apenas no brincar. Assim como a criança, ao brincar, vai depositando partes suas nos diversos personagens da trama da brincadeira, o mesmo ocorre quando se pede o relato de uma história diante de uma prancha projetiva, como o TAT de Murray (1943), ou ainda o Maps de Sneidman (1948, 1952).

A personificação pode ocorrer também por meio de animais ou objetos inanimados, que ganham a oportunidade de expressar fantasias. Por isto, recomenda-se colocar entre os materiais de brinquedo das sessões lúdicas, além de uma família humana, uma família de animais e um conjunto de objetos do mesmo tipo (em geral, carros). Assim, quando o uso de bonecos for muito ansiogênico, estes outros brinquedos poderão suportar as representações familiares (KLEIN, 1964a). Esta ideia também pode ser remetida a Freud (1905/1948). Ao refletir sobre os chistes, ele considera que outros elementos permitem a distribuição de fantasias: "Mais tarde, e por uma espécie de personificação bastante frequente, encontramos o cômico também nos animais, e nos objetos inanimados" (FREUD, 1905/1948, p.905). Até mesmo as figuras míticas, como anjos e demônios oferecem suporte para estes conteúdos, já que "o diabo nada mais é do que a personificação da vida instintiva reprimida inconscientemente" (FREUD, 1908/1948, p.952). 
Da mesma forma, um romancista, ao desenvolver seu enredo, também terá a oportunidade de depositar características da dinâmica interna de sua vida mental nos diversos heróis de sua trama. E é isto que faz o escritor Nelson Rodrigues - cuja vida passou por uma sucessão de tragédias - dizer que, se não fosse por seu ofício de escrever, teria enlouquecido (RODRIGUES, 1986). Com sua obra, exorcizava seus demônios e fantasmas, como fazem outros poetas e romancistas (RODRIGUES, 1965; SILVA, 1984; NUNES \& NUNES, 1989; CASTRO, 1992; CORRÊA, 2004).

\section{FORMAÇÃO DE COMPROMISSO}

Outro aspecto importante a salientar está no fato de a fantasia ser função de uma formação de compromisso. Este conceito freudiano é o resultado de uma espécie de contrato interativo que ocorre entre o Id, Ego e Superego (FREUD, 1900/1948). O objetivo deste compromisso firmado entre os três sistemas é a manutenção do equilíbrio psíquico. Nesta direção trabalham os mecanismos de defesa, que procuram solucionar os conflitos, evitar a angústia e manter a estrutura da personalidade (FREUD, 1968). Este trabalho fica nítido no sonho, no sintoma, no ato falho.

E quanto às aplicações projetivas? Seria possível afirmar a mesma coisa? Sem dúvida, já que a formação de compromisso ocorre também em outros comportamentos. Assim, sem sair do contexto freudiano, é possível afirmar que qualquer ato do ser humano vai ser gerado por meio de uma barganha interativa entre as três instâncias da personalidade, com as defesas desempenhando um papel central na manutenção do equilíbrio psíquico. A influência da metafísica materialista herbartiana mais uma vez fica nítida, já que, para Herbart, as respostas perceptivas aos estímulos externos configuram defesas autoprotetoras que obedecem ao princípio de resistência à destruição.

Voltando à tese freudiana, a obra do artista revela-se bastante sensível a este contrato subjetivo que ocorre entre as forças da personalidade. É possível ainda afirmar que o mesmo acontece durante uma aplicação projetiva, quando as respostas aos métodos projetivos também serão resultado de uma formação de compromisso.

\section{A PROJEÇÃO NA ARTE E NOS TESTES PSICOLÓGICOS}

Freud analisou a obra de alguns pintores, entre os quais Leonardo da Vinci (1910/1948) e Miguel Angelo (1914/1948), e escritores como Dostoievski (1927/1997), de quem vai examinar Os irmãos Karamázov e Crime e castigo. Na área da literatura, Freud tomou ainda a Gradiva de Jensen (1907/1948), algumas obras 
de Shakespeare, como Hamlet (1914/1948), e Macbeth (1901/1948, 1905/1948, 1914/1948), e de Goethe (1917/1948). Estes estudos contribuíram para a compreensão de que é impossível separar o artista de sua criação. Ao realizar sua obra, o artista a envolve com seu estilo pessoal, imprimindo uma espécie de marca registrada nas suas produções.

As leituras freudianas sobre as obras de arte forneceram uma excelente base para validar as técnicas projetivas da Psicologia. Os métodos projetivos afirmam a possibilidade de dizermos algo sobre alguém, por meio de sua produção, de suas visões diante de estímulos ambíguos. As experiências prévias influem nas percepções, e produzem entrelaçamentos que se materializam nas fantasias criadas frente a estímulos ambíguos. Tais criações acabam constituindo uma amostra válida e confiável do modo de ser da pessoa, de sua personalidade (ANZIEU, 1988; ABT \& BELLAK, 1967). A closura gestáltica das manchas do teste de Rorschach, o rabiscar de um desenho com as chamadas técnicas gráficas, ou ainda o relato de uma história nos testes temáticos ao estilo do TRO (Teste de Relações Objetais) de Phillipson (1981), ou do Ômega de Villas-Boas (1972) — todas estas atividades permitirão a leitura da vida psíquica.

A adesão a um enquadramento psicanalítico não deve entrar em contradição com a utilização de testes em um processo de psicodiagnóstico. Ao contrário, a dispensa sistemática destes recursos complementares pode traduzir um comportamento onipotente, no qual "imagina-se poder chegar magicamente à compreensão profunda do dinamismo inconsciente, através do poder de uma escuta e de um olhar privilegiadamente instrumentalizados pela teoria psicanalítica" (ROCHA-PINTO, 1997). A crítica que se faz às interpretações dos métodos projetivos como risco para subjetividades é ingênua, se se ignorar o fato de que a mesma coisa ocorre em relação à entrevista. Este é um forte motivo para completar as observações com outros meios, ao se fazer uma avaliação diagnóstica. Além disto, as fantasias e comportamentos observados numa entrevista são apenas parcelas, recortes de um quadro bem maior, justificando o uso de recursos complementares. Conforme Ocampo, psicanalista argentina: "Nesta situação (a criança) expressa somente um segmento de seu repertório de condutas, reatualizando no aqui e no agora um conjunto de fantasias e de relações de objeto que irão se sobrepor ao campo do estímulo. Por isso recorre-se, complementarmente, a outros instrumentos ou métodos de investigação" (OCAMPO e cols., 1978, p.169).

Estes instrumentos podem ser escolhidos entre os inúmeros testes que compõem o instrumental clínico, de acordo com cada caso. Exner (1974) lembra que na história do psicodiagnóstico, o psicólogo clínico tendeu a usar múltiplos procedimentos. Os fundamentos teóricos para esta utilização de um conjunto de testes foram bem desenvolvidos por diversos autores, como Bell (1951), Rapaport 
(1965), ou Cunha (2002), dentre outros. Os argumentos para o uso de múltiplas técnicas são de duas ordens: em primeiro lugar está a limitação dos instrumentos. Cada teste é idealizado para avaliar uma determinada característica ou função do sujeito. Uma avaliação mais complexa necessita de diferentes testes, que irão abordar então diferentes dimensões da personalidade. Em segundo lugar, o uso de um conjunto de instrumentos minimiza o erro e maximiza a adequação das avaliações pela validação cruzada, que pode ser alcançada por meio dos entrecruzamentos e superposições dos vários métodos. Assim, é possível conseguir uma amostragem mais ampla do comportamento, diminuindo a probabilidade de especulações (MURSTEIN, 1965).

Num esforço de sistematização, Anzieu (1988) classifica os testes em três categorias:

a) Técnicas expressivas: configuram situações nas quais há uma ampla liberdade, tanto de instruções, quanto do material utilizado.

b) Técnicas projetivas: com respostas livres, material definido e padronizado, embora ambíguo.

c) Testes psicométricos: para os quais o material exige uma grande precisão, e em que as respostas adequadas variam muito pouco.

Sua classificação poderia se tornar mais abrangente se Anzieu (idem) considerasse o conceito de projeção como categoria geral. Deste modo, poderia incluir, como categorias específicas, as técnicas temáticas, as estruturais e, ainda, incorporar também as técnicas expressivas, que fornecem ampla oportunidade para a projeção de fantasias. No entanto, em seu artigo, apenas as técnicas estruturais e temáticas são indicadas como especificações dos métodos projetivos. Métodos estruturais seriam aqueles que oferecem informações referentes à estrutura da personalidade. O protótipo seria o Teste de Rorschach (1921/1967). Embora Anzieu (idem) não especifique outros, é possível incluir nesta categoria o PMK (Psicodiagnóstico Miocinético de Mira y López,1987), ou o Teste das Pirâmides Coloridas, de Amaral (1966), técnicas que procuram investigar características e controles de caráter estrutural.

Como técnicas temáticas, Anzieu (idem) relaciona as tarefas que envolvem a preparação de uma história por parte do sujeito. Através da elaboração de temas e contos, a pessoa revela seus conflitos e desejos fundamentais, suas expectativas, modelos de reação, mecanismos de defesa, e os principais momentos da sua trajetória de vida. Todos os relatos livres se incluem como técnicas temáticas. Tais relatos são induzidos por estímulos padronizados, como as pranchas do CAT e do Maps, ou montados como tarefas de complementação, feito as histórias das Fábulas de Duss (DUSS, 1950).

Relatos livres podem ser solicitados também depois que alguém completou suas tarefas expressivas, tal como é uma prática mais ou menos comum nos 
desenhos do HTP — House, Tree, Person — de Buck (1964/2003), no teste do Desenho do Animal de Levy (1969), no Desenho do Professor de Klepsch (1984), ou mesmo no Teste das Garatujas, de Louis Corman (1971). Nesta última técnica gráfica, é possível pedir a associação de uma história após o desenho dos rabiscos. As histórias que surgem acabam emprestando um caráter temático a todas as técnicas gráficas.

As técnicas expressivas podem ser definidas como aquelas que investigam características de personalidade através dos padrões dos movimentos e ritmos corporais (SCHEEFFER, 1962). Assim, o comportamento expressivo caracteriza o estilo pessoal de resposta diante das situações. Neste sentido, as técnicas expressivas oferecem oportunidade para a pessoa reagir de forma característica ou individual, quando maneja e organiza um material. Para efeito de interpretação, é importante lembrar que as técnicas expressivas são simultaneamente projetivas. Cabe assinalar que elas "possibilitam uma exploração da personalidade mais global e livre do que se pode obter mediante o emprego de outros métodos, uma vez que a execução da tarefa proposta implica em um intenso grau de criação e elaboração pessoal” (PERES \& JUSTO, 2005, p.308).

Boa parte destes métodos expressivos apresenta a vantagem de não necessitar da linguagem falada. Ainda, são recursos que, além de servirem como instrumentos de diagnóstico, podem também ser usados como material terapêutico. Por meio das diversas oportunidades de autoexpressão oferecidas por tais técnicas, a pessoa "não apenas revela suas dificuldades, mas também se liberta delas" (ANASTASI, 1965, p.675). Entre as técnicas expressivas encontramos o desenho e a pintura, a atividade do brinquedo nas sessões livres, os testes lúdicos e, inclusive, toda a riqueza da mímica e dos movimentos que podem ser observados nas situações psicodramáticas. Entre todas estas técnicas, pelo menos duas - o grafismo e o brinquedo - são recursos bastante utilizados no psicodiagnóstico de crianças e adolescentes.

Os desenhos, por exemplo, podem ser toscos e grotescos, ou sofisticados, com a técnica se traduzindo em trabalhos bem elaborados. Ou podem expressar a maestria de grandes pintores como Da Vinci, Renoir ou Picasso. O estilo definitivo não importa. O que interessa é que todas as pinturas e desenhos, desde as garatujas de uma criança ao elegante e sofisticado traçado de um arquiteto, podem revelar o mundo interior de seu autor. A presença ou ausência do domínio consciente da gramática e da sintaxe da linguagem gráfica não impede a revelação da vida psíquica da pessoa.

Como nos lembra Hammer (1969), em seu livro sobre técnicas projetivas gráficas, os próprios pintores são os primeiros a reconhecer que, ao procurar retratar o mundo externo, o artista acaba criando uma realidade bastante subjetiva. Em suas pinturas, o pintor está sempre retratando duas pessoas — o modelo 
e a si mesmo. Existem múltiplas constatações desta vinculação entre o retrato e seu pintor. Mona Lisa já sugeriu diversas interpretações.

“O sorriso de Mona Lisa provavelmente não pertencia em absoluto à Mona Lisa; representava a perspectiva do próprio Leonardo Da Vinci diante da vida, e refletia a distraída superioridade da qual se armava para compensar seu ressentimento contra o pouco generoso tratamento que o destino lhe dera, e a frequente falta de reconhecimento do lugar que lhe correspondia na vida." (CARVEN, apud HAMMER, 1969, p.22)

Há diferenças acentuadas nos estilos dos pintores, e sua análise revela muito a respeito da personalidade de cada um. Até o elemento formal da cor pode ser utilizado como suporte para captar a projeção de sentimentos e ideias. As cores são elementos simbólicos, que podem mobilizar e expressar emoções e afetos. Alguns pintores preferem tons depressivos, disfóricos, angustiados e sombrios, como El Greco (1597-1599). Vista de Toledo parece traduzir um estado emocional de desalento e tristeza. O turbilhão de cores azuis e negras sugere um grande desespero diante da fragilidade da pequena cidade. Seria possível creditar parte dos sentimentos expressos nesta pintura à frustração das expectativas de viver em Madrid, na corte do Rei Felipe II, depois que este rejeitou um de seus quadros? O estilo sombrio deste pintor pode ser contrastado com o de Van Gogh (1853-1890), apaixonado pelas cores. O pintor holandês utiliza cores intensas, espessas, fortes e contrastantes, com tracejados rápidos e impulsivos. Das cartas que escreveu a seu irmão Theodore, é possível extrair todo um tratado sobre as cores. Sobre o vermelho utilizado em um de seus quadros, lembremos o que ele fala: "Quando pintei o Café Alcazar procurei dizer que o Café é um lugar onde a gente pode se arruinar, tornar-se um louco ou cometer crimes. Procurei exprimir com o vermelho e o verde as terríveis paixões humanas" (VAN GOGH, apud TAUSZ, 1976, p.48). O vermelho é uma cor que com frequência simboliza a possibilidade de a pessoa se desequilibrar, entregando-se a comportamentos muito impulsivos. Aliás, este é um dos significados atribuídos a esta cor, pela interpretação das Pirâmides Coloridas. Quanto ao amarelo, Van Gogh, uma autoridade nesta cor, afirmava que sem esta tonalidade, tudo que ele pintava ficava morto, sombrio e sem valor. Por isto, uma explosão de amarelo invade sua obra durante quatorze meses. Como resultado, ele conseguiu imprimir em suas telas uma potência de forças e movimentos, que surgem a partir da projeção na tela exterior de violentas paixões internas, tão vibrantes e rebeldes quanto seus torturados girassóis, ou seus brilhantes campos de trigos açoitados pelos ventos.

A revisão da literatura sobre textos de interpretação psicanalítica de obras artísticas, realizada por Rocha-Pinto (1995), lista vários artigos nos quais a 
literatura se mescla com a psicologia, explorando uma multiplicidade de questões. O programa do Institute for Psychological Study of the Arts, sediado na Universidade da Flórida, aplica conceitos psicológicos e psicanalíticos a diversas produções, como romances, artes visuais, filmes, e músicas. São comuns os trabalhos em que se procuram os motivos para o estilo de um determinado autor ou busca-se entender as razões para o perfil psicológico de um personagem de romance. Estas questões são as mesmas que o psicólogo se propõe quando diante das produções associadas aos estímulos dos métodos projetivos.

No entanto, é preciso evitar leituras reducionistas. É bem fácil encontrar trabalhos que reduzem o valor da obra artística às comprovações de uma teoria. O entusiasmo por um conceito ou teoria pode gerar insatisfações (TELLES, 2000). O autor do texto ou do desenho interpretado pode não concordar com os significados atribuídos à sua obra. Lembramos duas passagens que ilustram tal fato. A primeira pertence a Daniel Kuperman (1995), que escreveu uma crítica no Jornal do Brasil sobre o livro Os filmes que eu vi com Freud: "O autor não consegue evitar excessos da imaginação interpretativa que, se não são inverdades teóricas, arriscam-se a decepcionar o leitor que encontra personagens marcantes do cinema demasiadamente simplificados, senão reduzidos à 'exibição de doentes', para fins didáticos na academia médica” (KUPERMAN, 1995, p.4).

A segunda passagem refere-se à crítica ferina de Sonia Rodrigues Motta sobre um autor que procurou fazer uma leitura psicanalítica do teatro de Nelson Rodrigues:

"O livro perde quando o autor se dispõe a psicanalisar não os personagens, mas o autor das peças. (...) Temas recorrentes, e até obsessivos, como rivalidade entre irmãos, adultério, vingança, morte, incesto, não são uma característica exclusiva do universo rodrigueano. Mantendo-se no limite por ele mesmo proposto, do 'exame psicológico da obra de Nelson Rodrigues', Martuscello correria menos riscos do que ao levantar hipóteses sobre os aparentes 'desdobramentos projetivos da personalidade do autor', que lhe permitiriam expressar inconscientemente sua 'ambivalência de sentimentos em relação ao pai', ou 'os momentos em que o Édipo irrompe na obra teatral de Nelson', ou aqueles que supostamente revelam que 'em Nelson Rodrigues, a nostalgia da mãe é enorme'. Essas hipóteses são arriscadas no terreno da teoria porque Nelson Rodrigues não foi psicanalisado por Carmine Martuscello." (MOTTA, 1994, p.6)

De fato, interpretações muito radicais podem empobrecer o autor do texto, seja ele um escritor conhecido, um sujeito em processo de avaliação diagnóstica ou em psicoterapia. Freud arriscou-se a um reducionismo interpretativo, ao trabalhar sobre certas obras (CORREAA, 2004; NUNES \& NUNES, 1989). Em várias ocasiões inclinou-se a limitar a obra de Leonardo Da Vinci (FREUD, 
1910/1948) a uma fantasia incestuosa. E, quando trabalhou sobre o romance Gradiva, quase chega a transformar em delírio patológico aquilo que se constituía em intenso sentimento de paixão, a ponto de seu autor reagir mal à análise de sua narrativa. “Talvez seja preferível”, escreve Jensen, “atribuir a descrição dos processos psicológicos... à intuição poética.” (KRIS, 1968, p.20). Mas Freud era um gênio. Com intuição e sensibilidade conseguia gerar um amplo panorama sobre cada artista que analisou.

Afinal, o mundo da criação pode revelar algo da patologia ou da perversão que vive no interior do artista. Porém, a obra não pode ser demonizada e reduzida drasticamente aos conflitos pessoais de seu autor. Pois para além da projeção, a obra artística é uma interpretação criativa, crítica e singular do mundo. Da mesma forma, as produções que surgem diante dos métodos projetivos também não devem ser interpretadas de forma reducionista.

\section{CONCLUSÃO}

Fizemos aqui uma rápida abordagem sobre conceitos psicanalíticos que colaboram para apoiar os métodos projetivos. Examinamos quatro conceitos: a projeção e suas diferentes variações, a elaboração de fantasias, a personificação e a formação de compromisso. Porém, há vários outros constructos que também mereceriam atenção, já que podem oferecer fundamentos para a abordagem das técnicas projetivas. Por isto, consideramos importante a ampliação dos estudos sobre os fundamentos teóricos dos métodos projetivos, inclusive partindo-se de outras abordagens teóricas. Quanto mais claro ficarem os conceitos sobre os quais repousa a interpretação destes métodos, mais fácil será para o psicólogo ampliar suas habilidades e conhecimentos, de modo a qualificar-se melhor para o emprego das técnicas projetivas. Acreditamos que um melhor domínio sobre os conceitos básicos poderá aumentar a fidedignidade das interpretações por parte dos psicólogos. E, em decorrência, não apenas diminuir as resistências em relação a estes métodos, como fortalecer a confiança em seus resultados.

Uma segunda conclusão diz respeito à necessidade de sensibilidade, tato e conhecimento na interpretação destas técnicas. As associações produzidas precisam ser interpretadas com tato e cuidado. Ao se lidar com os materiais projetivos, a responsabilidade é muito grande, principalmente porque as interpretações não estarão expostas aos olhares críticos de observadores externos. Quando estão em jogo as associações produzidas a partir dos métodos projetivos, é preciso evitar, sobretudo, o risco de a interpretação revelar mais do intérprete do que do sujeito interpretado. 


\section{REFERÊNCIAS}

ABT, L. E. \& BELLAK, L. (1967) Psicologia proyectiva. Buenos Aires: Paidós. AMARAL, F. (1966) Pirâmides coloridas de Pfister. Rio de Janeiro: Cepa. ANASTASI, A. (1965) Testes psicológicos: teoria e aplicação. São Paulo: Herder. . \& URBINA, S. (2000) Testagem psicológica. Porto Alegre: Artmed.

ANZIEU, D. (1988) Os métodos projetivos. Rio de Janeiro: Campus.

BELLAK, L. (1967) "Sobre los problemas del concepto de proyección", in ABT, L. E. \& BELLAK, L. Psicologia proyectiva. Buenos Aires: Paidós.

BELL, J. E. (1951) Técnicas proyectivas. Buenos Aires: Paidós.

BUCK, J. (2003) Casa, árvore, pessoa: técnica projetiva de desenho: manual e guia de interpretação. São Paulo: Vetor.

CASTRO, R. (1992) O anjo pornográfico: a vida de Nelson Rodrigues. São Paulo: Companhia das Letras.

CORRÊA, C. (2004) Por que Shakespeare? O encontro de Freud com Shakespeare. Estudos de Psicanálise, Belo Horizonte, n.27, 19-26.

CORMAN, L. (1971) El test de los garabatos: exploración de la personalidad profunda. Argentina: Kapelusz.

CUNHA, J. A. e cols. (2002) Psicodiagnóstico V. Porto Alegre: ArtMed.

DUSS, L. (1950) La methode des fables en psychanalyse infantile. Paris: Arche.

EL GRECO (1580) View of Toledo. Metropolitan Museum of Art. Disponível em <http://www.metmuseum.org/toah/ho/08/eusi/ ho_29.100.6.htm>. Acesso em 13/08/2008.

EXNER, J. E. (1974) The Rorschach, a comprehensive system. New York: John Wiley \& Sons Inc.

FRANK, L.K. (1939) Projective Methods for the Study of Personality. Journal of Psychology: Interdisciplinary and Applied, v.8, 389-413.

. (1965) "Projective methods for the study of personality", in MURSTEIN, B. J. Handbook of projective techniques. New York: Basic Books.

FREUD, A. (1968) O ego e os mecanismos de defesa. Rio de Janeiro: Biblioteca Universal Popular.

FREUD, S. (1997) Edição eletrônica brasileira das obras psicológicas completas de Sigmund Freud. Rio de Janeiro: Editora Imago.

. (1948) Obras completas, v.I, II, III, Madrid: Biblioteca Nueva.

(1900) “La interpretación de los sueños”, v.I, p.231-581.

(1901-1904) "Psicopatologia de la vida cotidiana" v.I, p.627-766.

(1901-1904) “Determinismo. Fe Casual. Superstición. Consideraciones”, in Psicopatologia de la vida cotidiana, v.I, p.746-766.

(1905) "El chiste y su relación com lo inconsciente", v.I, p.819-930.

(1907) “El delirio y los sueños en 'La Gradiva' de W. Jensen”, v.I, p.583-626.

(1908a) "El poeta y la fantasia”, in Psicoanalisis Aplicado, v.II, p.9511053.

(1908b) “El caracter y el erotismo anal”, in Ensayos sobre la Vida Sexual y la Teoría de las Neurosis, v.I, p.931-1022.

(1910) “Un recuerdo infantil de Leonardo da Vinci”, v.II, p.365-401. 
(1911) "Observaciones psicoanaliticas sobre un caso de paranoia ('dementia paranoides') Autobiograficamente Descrito”, in Historiales clinicos, v.II, p.509-750.

(1913) “Totem y tabu”, v.II, p.419-507.

(1914) “El ‘Moisés' de Miguel Angel”, in Psicoanalisis Aplicado, v.II, p.977990.

(1914) "Varios tipos de carácter descubiertos en la labor analítica”, in Psicoanalisis Aplicado, v.II, p.993-1001.

(1917) “Un recuerdo infantil de Goethe en 'Poesía y Verdad' ”, v.II, p.1.036-1.041.

(1925) “Inibición, síntoma y angustia”, v.I, p.1.213-1.253.

(1928) “Dostoievsky y el parricídio”, v.II, p.1.044-1.053.

HAMMER, E. (1969) Tests proyectivos gráficos. Buenos Aires: Paidós.

HERBART, J. F. (1816/2008) A textbook in psychology: an attempt to found the science of psychology on experience, metaphysics, and mathematics. Translator Margaret K. Smith. Montana: Kessinger Publishing, LLC.

KLEIN, M. (1964a) El psicoanalisis de niños. Buenos Aires: Hormé. (1964b) Contribuciones al psicoanálisis. Buenos Aires: Hormé SAE.

KLEPSCH, M.\& LOGIE, L. (1984) Crianças desenham e se comunicam: uma introdução aos usos projetivos dos desenhos infantis da figura humana. Porto Alegre: Artes Médicas.

KRIS, E. (1968) Psicanálise da arte. São Paulo: Brasiliense.

KUPERMAN, D. (1995) Os filmes que eu vi com Freud, de Daniel Zuzman. Rio de Janeiro: Jornal do Brasil, Caderno B, 25/3/1995, p.4.

LEVY, S. (1969) “O teste do desenho do animal”, in HAMMER, E. Tests proyectivos gráficos. Buenos Aires: Paidós.

MIRA, A. M. G. (1987) Psicodiagnóstico miocinético. São Paulo: Vetor.

MOTTA, S. (1994) O teatro de Nelson Rodrigues: uma leitura psicanalítica, de Carmine Martuscello. Rio de Janeiro: O Globo, Segundo Caderno, 16/1/1994, p.6.

MURRAY, H. A. (1943) Thematic apperception test. Cambridge, MA, US: Harvard University Press.

MURSTEIN, J. (1965) Handbook of projective techniques. New York: Basic Books. NUNES, E. \& NUNES, P. (1989) Freud e Shakespeare. Rio de Janeiro: Imago.

OCAMPO, M., ARZENO, M., PICCOLO, E. y colab. (1978) Las técnicas proyectivas y el proceso psicodiagnóstico. Buenos Aires: Nueva Visión.

PERES, R. \& JUSTO, J. (2005) Contribuições das técnicas projetivas gráficas para a compreensão da personalidade de andarilhos de estrada, Estudos de Psicologia (Natal), 10 (2), maio-ago, 305-312.

PHILLIPSON, H. (1981) Test de relaciones objetales. Buenos Aires: Paidós.

RAPAPORT, D. (1965) Tests de diagnóstico psicologico. Buenos Aires: Paidós.

ROCHA-PINTO, E. (1997) A utilização dos testes no processo de psicodiagnóstico de crianças e adolescentes, Arquivos Brasileiros de Psicologia, $49(1)$.

(1995) A ética perversa de "álbum de família" — Leitura Psicanalítica de uma Peça de Nelson Rodrigues. Dissertação Mestrado em Psicologia Social e da Personalidade. Rio de Janeiro: Instituto de 
Psicologia da Universidade Federal do Rio de Janeiro.

RODRIGUES, N. (1965) Teatro quase completo. 4v. Rio de Janeiro: Tempo Brasileiro.

RODRIGUES, S. (1986) Nelson Rodrigues, meu irmão. Rio de Janeiro: José Olympio.

RORSCHACH, H. (1921/1967) Psicodiagnóstico. Rio de Janeiro: Mestre Jou.

ROSA, J. T. (Org.) (1995) Atualizações clínicas com o teste de relações objetais de Phillipson. São Paulo: Lemos.

SCHEEFFER, R. (1962) Introdução aos testes psicológicos. Rio de Janeiro: Fundação Getúlio Vargas.

SHNEIDMAN, E. S. (1948) Make a picture story. New York: The Psychological Corporation.

(1952) Projective techniques monographs: manual for the make a picture story method, n.2, July. California: The Society for Personality Assessment, Inc.

SILVA, V. (1984) Psicanálise da criação literária: as neuroses dos grandes escritores. Rio de Janeiro: Achiamé.

TAUSZ, B. (1976) A linguagem das cores. Rio de Janeiro: Atelier de Arte e Edições M.G.

TELLES, V. (2000) A desvinculação do TAT do conceito de "projeção" e a ampliação de seu uso. Psicol. USP 11(1).

VILLAS-BOAS, F. J. (1972) TPO — Teste Projetivo Ômega. Rio de Janeiro: Cepa. WOLMAN, B. B. (1970) Teorias y sistemas contemporâneos en psicología. Barcelona: Martinez Roca.

Elza Rocha Pinto

emrp@rio.matrix.com.br 